\title{
Amniotic membrane extract and eye drops: a review of literature and clinical application
}

This article was published in the following Dove Press journal:

Clinical Ophthalmology

\author{
Michael S Murri' \\ Majid Moshirfar ${ }^{1,2}$ \\ Orry C Birdsong² \\ Yasmyne C Ronquillo² \\ Yanning Ding ${ }^{2}$ \\ Phillip C Hoopes ${ }^{2}$ \\ 'John A Moran Eye Center, \\ Department of Ophthalmology and \\ Visual Sciences, University of Utah \\ School of Medicine, Salt Lake City, \\ UT, USA; ${ }^{2}$ HDR Research Center, \\ Hoopes Vision, Draper, UT, USA
}

\begin{abstract}
The amniotic membrane (AM) has a long history of use in the treatment of various diseases of the ocular surface. It contains pluripotent cells, highly organized collagen, anti-fibrotic and anti-inflammatory cytokines, immune-modulators, growth factors, and matrix proteins. It is used to promote corneal healing in severely damaged eyes. Recently, AM extract and AM extract eye drops have been successfully used in clinical applications, including dry eye and chemical burns. We provide an overview on the recent progress in the preparation, mechanisms of action, and use of AM extract/AM extract eye drops for corneal and external eye diseases.

Keywords: amniotic membrane, amniotic membrane extract, amniotic membrane extract eye drops, AME, AMEED, AMT, umbilical cord, amnion, Regenesol, Genesis, Regener-Eyes, corneal wound healing, amniotic membrane transplant
\end{abstract}

\section{Introduction}

Amniotic membrane (AM) has been utilized for many years as an adjuvant for tissue healing, with the first recorded use by Davis ${ }^{1}$ in 1910 during skin transplantation. Its use has continued to expand to the fields of orthopedics, sports medicine, urology, gynecology, plastic surgery, dentistry, and wound care. ${ }^{2-7}$ DeRoth is credited with the first ocular application of $\mathrm{AM} ;{ }^{8}$ however, the treatment had mixed results and fell out of favor with the ophthalmologic community until the early $1990 \mathrm{~s}$, when Battle ${ }^{9}$ reported applying AM for conjunctival defects and Kim and Tseng ${ }^{10}$ described using AM for ocular surface reconstruction. Since then, the use of AM in ocular surgery has become widespread. ${ }^{11-15}$ Currently, research is ongoing regarding the properties and therapeutic nature of various AM extract (AME). The purpose of this review is to explain the classification and properties of AM derivatives, summarize the experimental and clinical applications of AME eye drops (AMEED), comment on the current clinical trials and available products, and provide insight into the future application of these products.

\section{Classification and properties of amniotic membrane derivatives}

\section{Amniotic membrane}

The amniotic sac surrounds the fetus and comprises the amnion and chorion, both derived from the inner layer of the placenta. AM is part of the amnion and consists of a single layer of epithelial cells, a basement membrane, and an avascular connective tissue matrix, and is bathed in amniotic fluid. ${ }^{16}$ AM contains an extensive extracellular matrix, including collagen and laminins, cell-signaling proteins (cytokines), and growth factors. It has anti-inflammatory, anti-angiogenic, immunomodulatory, anti-bacterial, 
angio-modulatory, anti-scarring, and hemocompatibility properties. ${ }^{17}$

Most of the beneficial effects of AM are attributed to biomolecules, such as fibronectin, hepatocyte growth factor (HGF), epidermal growth factor (EGF), basic fibroblast growth factor (bFGF), transforming growth factor (TGF), and collagen types I, III, IV, and V, which are potent sources for corneal regeneration. ${ }^{18}$ They combine to facilitate migration, adhesion, and differentiation of the corneal epithelium, while preventing apoptosis. AM downregulates the expression of such cell surface markers as CD80, CD86, and major histocompatibility complex class 2 antigen, which are modulators of the immune response. In addition, secreted pro-inflammatory cytokines, such as tumor necrosis factor-alpha and IL-6 are reduced, while anti-inflammatory cytokines, such as IL-10 are upregulated. This, in turn, decreases inflammation, while the reduction of TGF-1 and TGF-2 inhibits fibrosis. ${ }^{19}$ These mechanisms combine to promote wound healing and regeneration (Figure 1). A comprehensive discussion of cytokine action and immune pathways is outside of the scope of this review, but has been extensively described in the literature..$^{20,21}$

AM is often used in ophthalmology for AM transplant (AMT), which is most often performed with fresh AM. However, AM may also be lyophilized, stored, and then rehydrated upon use, known commercially as human AM elementary units.

\section{Amniotic membrane extract}

AME contains many of the similar properties of cryopreserved AM. ${ }^{18}$ Similar to AM, it has high levels of a myriad of growth factors, including EGF, HGF, bFGF, protease inhibitors, and a novel matrix component known as heavy chain-hyaluronan pentraxin 3 (HC-HA/PTX3), which acts to prevent inflammation, angiogenesis, and scarring. ${ }^{17,22} \mathrm{AME}$ retains anti-inflammatory activities and often acts through downregulating and inducing apoptosis in macrophages. ${ }^{23}$

\section{Amniotic membrane extract eye drops}

AME is often produced for use in other fields of medicine as a topical or injectable, while AMEED is defined as AME designated specifically for ophthalmic use. For the purpose of this review, we will use AME generally and AMEED specifically when referring to ophthalmologic application, although we acknowledge an overlap in these terms. In addition, AME may be combined with umbilical cord (UC) blood as another type of AM-derived solution. This combination may be advantageous because the active matrix component responsible for exerting AM's anti-inflammatory effects (HC-HA/PTX3 complex) is also found in the UC

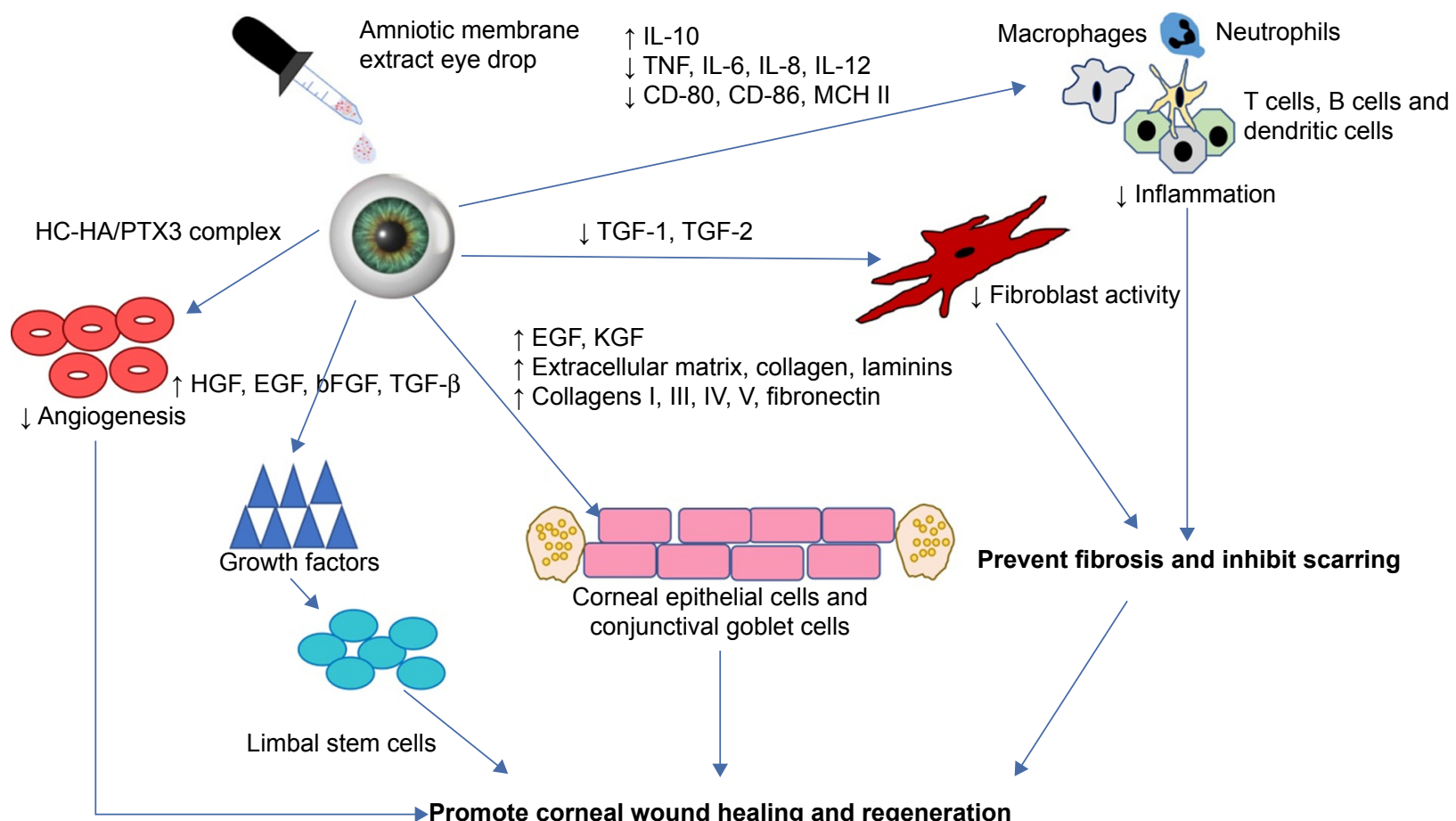

Figure I Proposed mechanism of AMEED role in promoting wound healing.

Abbreviations: AMEED, amniotic membrane extract eye drops; bFGF, basic fibroblast growth factor; EGF, epidermal growth factor; HGF, hepatocyte growth factor; IL, interleukin; KGF, keratinocyte growth factor; TGF, transforming growth factor; TNF, tumor necrosis factor. 
at significantly greater quantities and because UC is more effective than AM in inhibiting inflammatory markers. ${ }^{24}$ A proposed mechanism of AMEED's action on the ocular surface is represented in Figure 1.

\section{Amniotic fluid (AF)}

$\mathrm{AF}$ is a dynamic environment, which undergoes multiple developmental changes. AF contains electrolytes, growth factors, carbohydrates, lipids, proteins, amino acids, lactate, pyruvate, enzymes, and hormones. ${ }^{25}$ The presence of multiple growth factors, such as vascular endothelial growth factor, TGFB1, TGFB3, and growth differentiating factor-11 can promote cell growth and regeneration of healthy collagens I, II, III, IV, V, and VI that help promote healing. AF has been reported to be immune privileged. ${ }^{25}$ Although the composition of AF changes substantially, with increasing fetal urine and lung secretions as the gestation progresses, pluripotent stem cells have been isolated from full-term $\mathrm{AF} .{ }^{26}$

\section{Preparation of AME and AMEED}

There are various methods for the preparation of AME and AMEED, without consistent standardization. One method for the preparation of AMEED consists of washing isolated human AM with normal saline (containing 5\% penicillin and streptomycin), slicing into small pieces (with a scalpel blade), and submerging in liquid nitrogen. The mixture is homogenized, centrifuged and the supernatant is collected, centrifuged again, and sterilized by passage through a $0.25 \mathrm{~mm}$ filter (Millipore, Billerica, MA, USA). ${ }^{17}$ Other methods involve pulverization, micronization, or morselization of cryopreserved or dehydrated AM.

Different preparation methods may yield different amounts of bioactive components. In one study of AME, extracted HGF was $20 \%$ higher with pulverization compared with homogenization. ${ }^{10}$ The use of protease inhibitor also increased the amount of extracted HGF. Repeating centrifugation can double the extracted HGF. Storing the AME at $-170^{\circ} \mathrm{F}$ for 6 months caused a $50 \%$ drop in the level of HGF and protein. ${ }^{27}$

\section{Experimental studies on AME/AMEED}

The studies on AME/AMEED are summarized in Table 1. In one study, AMEED showed a potential benefit in acute corneal injuries when human corneal epithelial cells and human limbal cells treated with AMEED healed faster after mechanical insult. ${ }^{18}$ In vitro and in vivo studies reveal that AMEED supports proliferation and differentiation of corneal epithelial cells, enhances epithelial wound healing, and inhibits corneal neovascularization. ${ }^{17}$ AMEED was as effective as transplanted AM in healing corneal damage in a rabbit model. ${ }^{28}$

Freeze dried bovine AME was used successfully as a wound healing agent in a rabbit model. ${ }^{29} \mathrm{~A}$ whole thickness biopsy punch $(8 \mathrm{~mm})$ obtained from rabbit ear was taken and intradermal injections of AME fluid on 4 wound sites were

Table I Studies on AME and AMEED

\begin{tabular}{|c|c|c|c|}
\hline Author/year & AM preparation & Application & Results \\
\hline Chang et al $(2002)^{30}$ & AME & UVB irradiation of $\mathrm{HaCaT}$ cell & $\begin{array}{l}\text { Downregulation of inducible nitric oxide synthase mRNA } \\
\text { and decreased generation of nitric oxide; decreased } \\
\text { destruction of normal cells and tissues }\end{array}$ \\
\hline Bonci et al $(2005)^{38}$ & AMEED & Burns, ulcers & $\begin{array}{l}\text { Negative corneal staining to fluorescein after 15-20 days in } \\
\text { all patients' eyes }\end{array}$ \\
\hline He et al $(2008)^{23}$ & AME & Anti-inflammatory; low immunogenity & $\begin{array}{l}\text { Downregulation of macrophage activation and promotion of } \\
\text { macrophage apoptosis; pro-inflammatory cytokines reduced; } \\
\text { anti-inflammatory cytokines upregulated; downregulation of } \\
\text { surface markers and major histocompatibility complex class } \\
2 \text { antigen expression }\end{array}$ \\
\hline Shahriari et al $(2008)^{37}$ & AMEED & $\begin{array}{l}\text { Alkaline corneal epithelial wound in } \\
\text { rabbits }\end{array}$ & $\begin{array}{l}\text { Acceleration of wound healing with AM suspension } \\
\text { compared with autologous serum or preservative-free } \\
\text { artificial tears }\end{array}$ \\
\hline Liang et al (2009) $)^{31}$ & AMEED & Acute or chronic chemical burns & Inflammation reduced in all patients' eyes \\
\hline Sheha et al $(2010)^{32}$ & AMEED & Acute chemical burn & $\begin{array}{l}\text { Pain significantly relieved and inflammation was markedly } \\
\text { reduced in all cases of chemical burn }\end{array}$ \\
\hline Guo et al $(20 I I)^{28}$ & AMEED & Artificial corneal wounds in rabbit eyes & AM homogenate as effective as $A M$ transplant \\
\hline Gourabi et al $(2012)^{39}$ & AMEED & Unilateral corneal stem cell damage & Promotion of corneal epithelial healing in unilateral LSCD \\
\hline Dudok et al $(2015)^{18}$ & AME & Acute corneal injury & Acceleration of healing in human corneal epithelial cells \\
\hline Gourabi et al $(2015)^{40}$ & AMEED & Corneal epithelial healing & $\begin{array}{l}\text { Acceleration of corneal epithelial healing (Phase I and II } \\
\text { clinical trial) }\end{array}$ \\
\hline
\end{tabular}

Abbreviations: AM, amniotic membrane; AME, amniotic membrane extract; AMEED, amniotic membrane extract eye drops; LSCD, limbal stem cell deficiency; UVB, ultraviolet B. 
performed at 1 hour prior to injury, and at 1, 2, and 3 days post-injury. AME-treated cells significantly increased wound closure with $54.9 \%$ compared with control. The results of the study verified the feasibility of dermal injections of freezedried AME as a potential wound healing substrate, which can promote epidermal and dermal regeneration, while avoiding undesirable hyperproliferation of damaged tissue.

Finally, AME downregulated the induction of inducible nitric oxide (NO) synthase mRNA and decreased generation of NO by UVB irradiation in HaCaT cell (immortalized human keratinocyte cell line). ${ }^{30}$ At high levels, NO is a potent cellular toxin, either protecting the body against invading pathogens and tumor cells or destroying normal cells and tissues. Thus, AME was able to protect human keratinocytes against NO-induced damage.

\section{Clinical applications of AME/AMEED}

There are many small studies detailing various uses for AME and AMEED. In one prospective non-comparative interventional case series, 14 eyes of 11 patients with acute or chronic chemical burns received AMEED topically in combination with traditional treatment. Traditional treatment included topical prophylactic antibiotics, lubricants, cycloplegics, 10\% ascorbic acid and 6\% citrate, and topical steroid in acute cases. Chronic cases had received 2-4 weeks of topical $20 \%$ autologous serum and bandage contact lens without improvement. After AMEED therapy, the epithelial defect healed in all eyes with acute burns, in which $<7$ clock hours of limbus was involved, after 16.6 days of AMEED treatment. AMEED failed to close the epithelial defect in all eyes with chronic chemical burn and coexisting diffuse limbal stem cell deficiency (LSCD); however, the area of epithelial defect decreased to $58 \%$ at the final visit. Thus, AMEED may reduce inflammation and promote reepithelialization in the treatment of chemical burns, especially for mild-to-moderate acute cases. ${ }^{31}$ In another study, topical application of AMEED relieved pain and reduced inflammation in 6 eyes of 4 patients with mild-to-moderate acute chemical burn that had previously exhibited persistent epithelial defect (PED), inflammation, and haze despite extensive conventional therapy. ${ }^{32}$

AMEED may be helpful in the treatment of corneal abrasion leading to PED. A combination eye drops of morselized cryopreserved amniotic membrane and umbilical cord (AMUC) serum was reported to promote reepithelialization in a murine corneal abrasion model. ${ }^{24}$ AMUC has also been effective in promoting healing of PED in 4 patients presenting with cicatricial ocular diseases. ${ }^{33}$ In addition, AMEED has been successfully used in the treatment of many conditions, such as PED, ${ }^{34}$ partial LSCD, bullous keratopathy, corneoscleral ulcers, and in the acute stage of chemical burns. ${ }^{17}$

Often AMEED has been studied either in conjunction or in comparison with AMT with or without limbal transplantation. Using AMEED can extend the treatment time period when compared with AMT by providing active growth factors and compounds over a greater length of time to damaged corneal cells. It is important to note though that AMEED does not retain the structural properties of the AM. When used in concert, AMT and AMEED may synergistically promote stability of the ocular surface, stem cell growth, and differentiation of the corneal epithelium. ${ }^{17}$ In one recent study, supplemental AMEED, after limbal block transplantation, promoted regeneration of corneal epithelium in patients with total unilateral LSCD. This was compared with traditional treatment only consisting of topical antibiotics, corticosteroid drops, lubricating gel, and preservative-free artificial tears. These patients had regression of the conjunctivalization and vascularization of their cornea 2-3 months post-surgery. After sequential penetrating keratoplasty, all 4 transplanted corneas in the AMEED treatment group were clear. In the control group, that did not receive AMEED treatment, PED occurred. This provides evidence that it is not sufficient to treat limbal cell deficiency with transplantation, but is best supplemented with AMEED. In addition, this surgery's lasting effects of increased clarity of the cornea and decreased vascularity and conjunctivalization imply that the covering epithelial cells may be of a progenitor nature. ${ }^{17}$

Authors of the study found as well that the results were verified when histopathological analyses of the corneal buttons of eyes after corneal transplantation revealed the presence of LSC markers ( $\mathrm{p} 63 \mathrm{p}$ and ABCG2p cells). ${ }^{17}$ The evidence supports that AMEED might be involved in extension of the limbal cells over the ocular surface in vivo.

\section{Commercial products}

There are many companies, both domestic and international, that produce products derived from the AM. To our knowledge, none of these products are currently US Food and Drug Administration regulated. However, several of these products have obtained proper approval for distribution. The most established of these companies are Regenesol ${ }^{\mathrm{TM}}$ by Biotissue/Tissue Tech Inc. (Miami, FL, USA), Genesis Amniotic Cytokine Extract (ACE) ${ }^{\mathrm{TM}}$ by Ocular Science Inc. (Manhattan Beach, CA, USA) and Regener-Eyes ${ }^{\text {TM }}$ (Palm Beach, FL, USA). Regenesol is a morselized AMUC product 
in a gel form to be used twice a day with suggested application in post photorefractive keratectomy (PRK), phototherapeutic keratectomy (PTK), Epi-off cross-linking, and dry eye patients. Genesis ACETM is an ACE drop derived from AM through cryopreservation, with recommended topical application twice a day for a 30 -day treatment period. This product is advertised for use in dry eye, chemical burn, corneal ulcers, and post-LASEK and corneal transplant treatment. RegenerEyes, in contrast to the previously mentioned companies, markets an AF product, which is dosed 1-4 times daily for dry eye symptoms. Other companies based in South Africa, Italy, Spain, and the USA also market AME/AMEED products. The currently available products, methods of production, and marketed applications are detailed in Table 2.

\section{Clinical trials}

AME and its derivatives (AMEED, AMUC) may be useful as adjunctive treatment in patients with corneal erosion, chemical burns, and LSCD. They may also be useful as an additional treatment in peripheral corneal ulcers, such as Terrien's and Mooren's after corneal, limbal, corneo-scleral, and AMTs. In general, AME can be used to promote healing after injury due to inflammation (non-healing corneal ulceration), infection, trauma (chemical or thermal injury), or surgery (PRK and limbal transplants). However, clinical trials are needed to validate these uses.

There are only 2 completed clinical trials on AMEED reported on ClinicalTrials.gov. The first is "Utilization of Amniotic Membrane Extract Eye Drop (AMEED) on Human Corneal Healing" and the second is "The Improvement of Limbal Stem Cell Deficiency (LSCD) in Unilateral Stem Cell Damage by AMEED." Both studies are from Labafi Nejad Eye Research Center in Tehran, Iran (Table 1). ${ }^{39,40}$

There is one completed clinical trial on "Amnion-derived Cellular Cytokine Solution (ACCS) Eye Drops in the treatment of dry eye" from Price Vision group, Noveome Biotherapeutics. However, results are not currently available (Table 1). ${ }^{41}$ Two clinical trials are currently underway: 1 trial on the use of AF for the treatment of ocular Chronic Graft-Versus-Host Disease at the University of Utah and 1 Phase III clinical trial of the Regenesol AME gel product for post-PRK patients at Walter Reed National Military Medical Center (Table 1). ${ }^{42}$

\section{Advantages of AME/AMEED}

One advantage of AMEED is its potential use as a replacement for AMT. The AM used for transplant is often denuded of epithelial cells through cryopreservation. Most AME preparations are from cryopreserved, denuded AM. AME, if prepared from fresh tissue, may contain epithelial cells that may help in regeneration as stem cells. In addition, AMEED does not require an operative procedure and treatment can be continued until healing occurs. Used in conjunction with AMT, it may prolong the efficacy of AMT through the intermittent delivery of the necessary molecular modulators.

\section{Disadvantages and future direction of AME/AMEED}

The manufacturing processes for AME are varied and nonstandardized and most human placental membranes products are devitalized after dehydration and irradiation. The effects of the various methods of preserving AM before AME production have not been fully studied, and after production, the non-preserved drops have a short shelf life. There are challenges in proper preservation of AME without compromising effectiveness through dehydration, irradiation, or cryopreservation. Each different method of processing and preserving AM may lead to changes in the structural or functional properties of the various active biomolecules. Thus, bioassays of the various products and derivatives of AM should be performed, and products standardized. Microbiologic safety and the usual screening procedures for donors need to be scrupulously documented and kept.

The beneficial effects of AMEED should be validated with additional controlled clinical trials. There are no studies on which type of AM extraction technique yields the highest levels of the important modulators and there is no standardized assay to determine the biomolecules of each type of AME or AM derivative. A reliable standardized assay would be of key importance due to the inherent variability in the concentration of growth factors depending on the donor, procedure or purification, and time point in gestation in which the product is obtained. Further study is needed on whether the amnion, chorion, AF, UC blood, or some combination of these are most effective. Finally, there are no studies involving a comparison of AME with autologous blood-derived products, such as serum, plateletrich plasma, plasma rich in growth factors, and others, which have been studied in relation to ocular surface disorders. ${ }^{35,36}$ It is currently unknown whether these products are inferior, superior, or useful as an adjunct to AMEED. Thus, there is a large body of knowledge to be gathered before these products can be fully endorsed. 


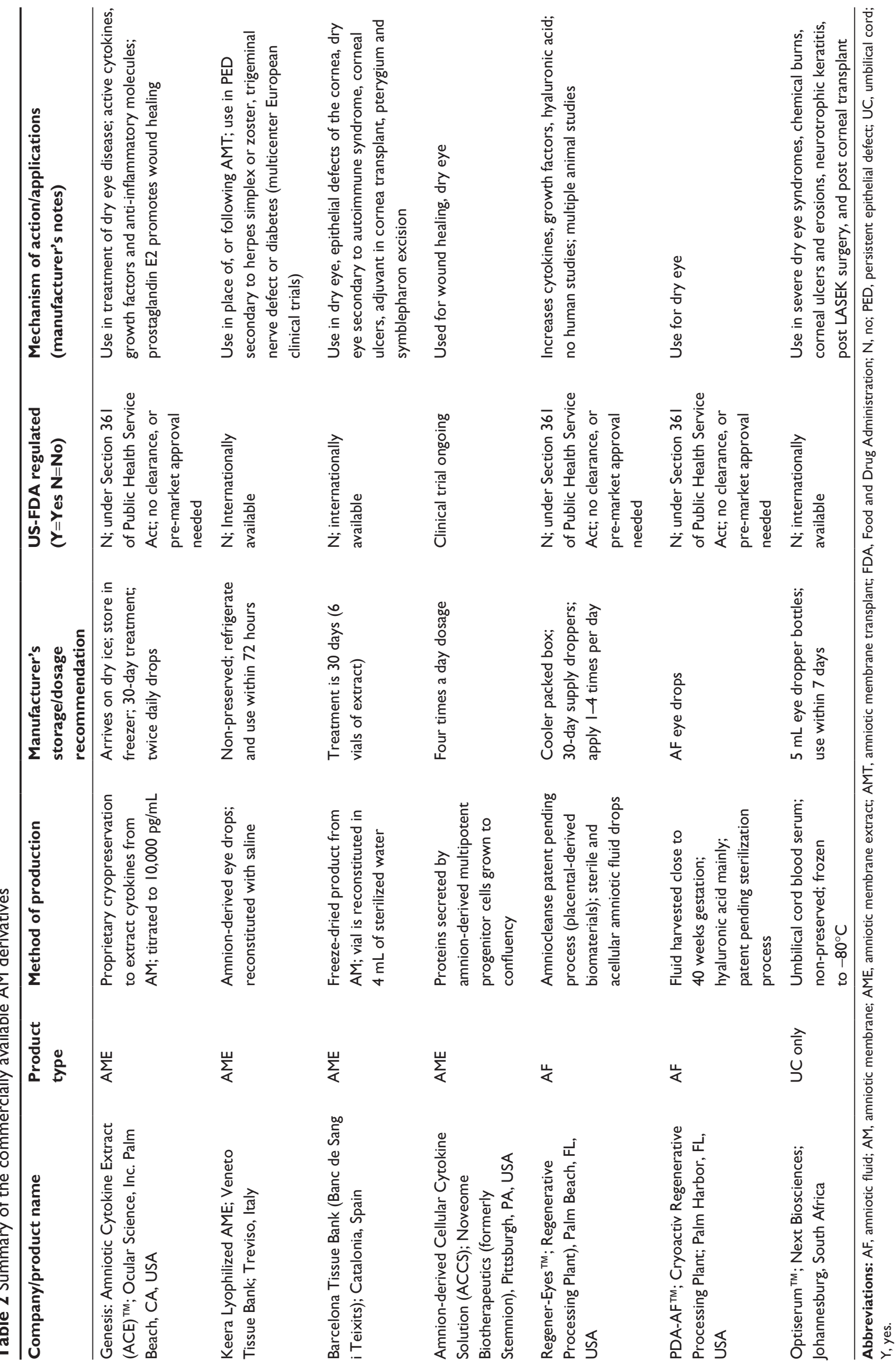




\section{Conclusion}

AME and AMEED have the potential for increased clinical use in corneal surface disorders. There is a need for additional clinical trials to determine standardization and efficacy of these products. While there are no reports of recognized complications of treatment using AMEED, a longer observation period and a larger patient population are necessary to validate its safety. However, with standardization of production, better preservation of AM prior to processing, stabilization of biological activities, and adequate well-designed clinical trials, AME and its derivatives are potentially useful as a treatment option for ocular surface disorders and an adjunct to surgical procedures, such as AMT and limbal grafts.

\section{Acknowledgments}

This study was funded by an unrestricted Grant from Research to Prevent Blindness (RPB), 360 Lexington Avenue, 22nd Floor New York, NY 10017, USA. No support was received for the publication of this article.

\section{Author contributions}

All authors contributed toward data analysis, drafting and revising the paper and agree to be accountable for all aspects of the work.

\section{Disclosure}

The authors report no conflicts of interest in this work.

\section{References}

1. Davis JS. Skin transplantation with a review of 550 cases at the Johns Hopkins Hospital. Johns Hopkins Med J. 1910;14:307-396.

2. Ashworth MF, Morton KE, Dewhurst J, Lilford RJ, Bates RG. Vaginoplasty using amnion. Obstet Gynecol. 1986;67(3):443-446.

3. Ward DJ, Bennett JP. The long-term results of the use of human amnion in the treatment of leg ulcers. Br J Plast Surg. 1984;37(2):191-193.

4. Gruss JS, Jirsch DW. Human amniotic membrane: a versatile wound dressing. Can Med Assoc J. 1978;118(10):1237-1246.

5. Gupta A, Kedige SD, Jain K. Amnion and chorion membranes: potential stem cell reservoir with wide applications in periodontics. Int $J$ Biomater. 2015;2015:274082.

6. Subrahmanyam M. Amniotic membrane as a cover for microskin grafts. Br J Plast Surg. 1995;48(7):477-478.

7. McIntyre JA, Jones IA, Danilkovich A, Vangsness CT Jr. The placenta: applications in orthopaedic sports medicine. Am J Sports Med. 2018;46(1):234-247.

8. de Rotth A. Plastic repair of conjunctival defects with fetal membranes. Arch Ophthalmol. 1940;23(3):522-525.

9. Batlle JF, Perdomo FJ. Placental membranes as a conjunctival substitute. Ophthalmol. 1993;100:A107.

10. Kim JC, Tseng SC. Transplantation of preserved human amniotic membrane for surface reconstruction in severely damaged rabbit corneas. Cornea. 1995;14(5):473-484.

11. Tseng SC, Prabhasawat P, Lee SH. Amniotic membrane transplantation for conjunctival surface reconstruction. Am J Ophthalmol. 1997; 124(6):765-774.
12. Meller D, Maskin SL, Pires RT, Tseng SC. Amniotic membrane transplantation for symptomatic conjunctivochalasis refractory to medical treatments. Cornea. 2000;19(6):796-803.

13. Anderson DF, Ellies P, Pires R, Tseng S. Amniotic membrane transplantation for partial limbal stem cell deficiency. Br J Ophthalmol. 2001;85(5):567-575.

14. Solomon A, Meller D, Prabhasawat P, et al. Amniotic membrane grafts for nontraumatic corneal perforations, descemetoceles, and deep ulcers. Ophthalmology. 2002;109(4):694-703.

15. Kruse FE, Rohrschneider K, Völcker HE. Multilayer amniotic membrane transplantation for reconstruction of deep corneal ulcers. Ophthalmology. 1999;106(8):1504-1511.

16. Koob TJ, Lim JJ, Zabek N, Massee M. Cytokines in single layer amnion allografts compared to multilayer amnion/chorion allografts for wound healing. J Biomed Mater Res B Appl Biomater. 2015;103(5):1133-1140.

17. Baradaran-Rafii A, Asl NS, Ebrahimi M, et al. The role of amniotic membrane extract eye drop (AMEED) in in vivo cultivation of limbal stem cells. Ocul Surf. 2017;16(1):146-153.

18. Dudok DV, Nagdee I, Cheung K, et al. Effects of amniotic membrane extract on primary human corneal epithelial and limbal cells. Clin Exp Ophthalmol. 2015;43(5):443-448.

19. Dua HS, Rahman I, Miri A, Said DG. Variations in amniotic membrane: relevance for clinical applications. Br J Ophthalmol. 2010;94(8):963-964.

20. Dinarello CA. Historical review of cytokines. Eur J Immunol. 2007; 37(Suppl 1):S34-S45.

21. Turner MD, Nedjai B, Hurst T, Pennington DJ. Cytokines and chemokines: at the crossroads of cell signalling and inflammatory disease. Biochim Biophys Acta. 2014;1843(11):2563-2582.

22. Shay E, He H, Sakurai S, Tseng SC. Inhibition of angiogenesis by HC.HA, a complex of hyaluronan and the heavy chain of inter-alphainhibitor, purified from human amniotic membrane. Invest Ophthalmol Vis Sci. 2011;52(5):2669-2678.

23. He H, Li W, Chen SY, et al. Suppression of activation and induction of apoptosis in RAW264.7 cells by amniotic membrane extract. Invest Ophthalmol Vis Sci. 2008;49(10):4468-4475.

24. Tighe S, Moein HR, Chua L, Cheng A, Hamrah P, Tseng SC. Topical cryopreserved amniotic membrane and umbilical cord eye drops promote re-epithelialization in a murine corneal abrasion model. Invest Ophthalmol Vis Sci. 2017;58(3):1586-1593.

25. Rennie K, Gruslin A, Hengstschläger M, et al. Applications of amniotic membrane and fluid in stem cell biology and regenerative medicine. Stem Cells Int. 2012;2012:721538.

26. Hamid AA, Joharry MK, Mun-Fun H, et al. Highly potent stem cells from full-term amniotic fluid: a realistic perspective. Reprod Biol. 2017; 17(1):9-18.

27. Mahbod M, Shahhoseini S, Khabazkhoob M, et al. Amniotic membrane extract preparation: what is the best method? JOphthalmic Vis Res. 2014; 9(3):314-319.

28. Guo Q, Hao J, Yang Q, Guan L, Ouyang S, Wang J. A comparison of the effectiveness between amniotic membrane homogenate and transplanted amniotic membrane in healing corneal damage in a rabbit model. Acta Ophthalmol. 2011;89(4):e315-e319.

29. Kang M, Choi S, Cho Lee AR. Effect of freeze dried bovine amniotic membrane extract on full thickness wound healing. Arch Pharm Res. 2013;36(4):472-478.

30. Chang DS, Seo SJ, Hong CK. The effect of amniotic membrane extract on the expression of iNOS mRNA and generation of NO in HaCaT cell by ultraviolet B irradiation. Photodermatol Photoimmunol Photomed. 2002;18(6):280-286.

31. Liang L, Li W, Ling S, et al. Amniotic membrane extraction solution for ocular chemical burns. Clin Exp Ophthalmol. 2009;37(9):855-863.

32. Sheha H, Liang L, Hashem H, Ramzy M, Zaki A. Amniotic membrane extract for acute ocular chemical burns. Tech Ophthalmol. 2010;8(4): $146-150$.

33. Cheng AM, Chua L, Casas V, Tseng SC. Morselized amniotic membrane tissue for refractory corneal epithelial defects in cicatricial ocular surface diseases. Transl Vis Sci Technol. 2016;5(3):9. 
34. Kordic R, Suic SP, Jandrokovic S, et al. Application of the amniotic membrane extract (AMX) for the persistent epithelial defect (PED) of the cornea. Coll Antropol. 2013;37(Suppl 1):161-164.

35. Alio JL, Rodriguez AE, WróbelDudzińska D. Eye platelet-rich plasma in the treatment of ocular surface disorders. Curr Opin Ophthalmol. 2015;26(4):325-332.

36. Pan Q, Angelina A, Zambrano A, et al. Autologous serum eye drops for dry eye. Cochrane Database Syst Rev. 2013;8(8):CD009327.

37. Shahriari HA, Tokhmehchi F, Reza M, Hashemi NF. Comparison of the effect of amniotic membrane suspension and autologous serum on alkaline corneal epithelial wound healing in the rabbit model. Cornea. 2008;27(10):1148-1150.

38. Bonci P, Bonci P, Lia A. Suspension made with amniotic membrane: clinical trial. Eur J Ophthalmol. 2005;15(4):441-445.

39. Royan Institute. The Improvement of Limbal Stem Cell Deficiency (LSCD) in Unilateral Stem Cell Damage by Amniotic Membrane Extract Eye Drop (AMEED). Available from: https:/www.clinicaltrials. gov/ct2/show/NCT02649621?cond=amniotic + membrane+extract\&ran k=2. NLM identifier: NCT02649621. Accessed May 1, 2018.
40. Royan Institute. Utilization of Amniotic Membrane Extract Eye Drop (AMEED) on Human Corneal Healing. Available from: https://www. clinicaltrials.gov/ct2/show/NCT02746848? cond=amniotic + membrane + ex tract\&rank=1. NLM identifier: NCT02746848. Accessed May 1, 2018.

41. Noveome Biotherapeutics. Study of ACCS Eye Drops in Treating Dry Eye. Available from: https://ClinicalTrials.gov/show/NCT02369861. NLM identifier: NCT02369861. Accessed May 1, 2018.

42. University of Utah. Study for the Treatment of Ocular Chronic GraftVersus-Host Disease (GVHD) With Amniotic Fluid Eye Drops (AFED). Available from: https://ClinicalTrials.gov/show/NCT03298815. NLM identifier: NCT03298815. Accessed May 1, 2018.
Clinical Ophthalmology

\section{Publish your work in this journal}

Clinical Ophthalmology is an international, peer-reviewed journal covering all subspecialties within ophthalmology. Key topics include: Optometry; Visual science; Pharmacology and drug therapy in eye diseases; Basic Sciences; Primary and Secondary eye care; Patient Safety and Quality of Care Improvements. This journal is indexed on

\section{Dovepress}

PubMed Central and CAS, and is the official journal of The Society of Clinical Ophthalmology (SCO). The manuscript management system is completely online and includes a very quick and fair peer-review system, which is all easy to use. Visit http://www.dovepress.com/ testimonials.php to read real quotes from published authors. 